\title{
Unlocking the Future of Learning by Redesigning Educator Learning
}

\author{
Adam Rubin and Ali Brown
}

\section{Today's Model of Learning: Our Challenge}

Our systems of public education were built in a different era, with a set of clear underlying objectives - to sort and filter students to a set of clear outcomes, as well as to inculcate them with a national identity.

Depending on the society, there may have been some variance, but there were clear commonalities across all systems. Those objectives made sense at the time and by and large, many systems had successful outcomes. We needed citizens first and foremost, bound together with a common story-both an understanding of a unified history and an aspirational narrative for their futures. Additionally, we needed a sorting mechanism as illustrated in Fig. 7.1, that helped send people to the farm, the factory and over time, a growing knowledge economy through which college was the portal. As national economies evolved, advances in transportation and telecommunications shrunk distances, and a global

\footnotetext{
A. Rubin $(\square) \cdot$ A. Brown

2Revolutions, LLC, Burlington, VT, USA

e-mail: adam@2revolutions.net
}

A. Brown
e-mail: ali@2revolutions.net

(C) The Author(s) 2019

J. W. Cook (ed.), Sustainability, Human Well-Being, and the Future of Education, https://doi.org/10.1007/978-3-319-78580-6_7 


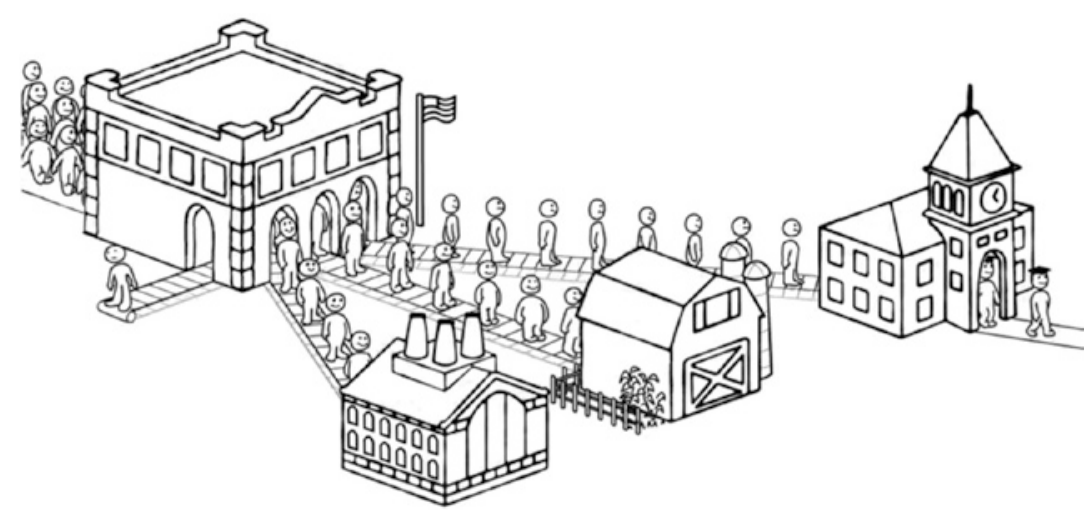

Fig. 7.1 The conveyer belt (Still taken from 2Revolutions' Future of Learning video)

economy emerged in the second half of the twentieth century that fundamentally shifted our labor needs. Farm and factory roles increasingly shifted to lower cost parts of the world, and lower wage, less growth-oriented jobs in the retail sector and the like developed as underwhelming alternatives. The impact of these shifts was compounded by significantly reduced demand for low-skill jobs because of improvements in technology. Our global economy had shifted, but the structure of our systems of education remained largely intact. This mismatch posed an increasing problem for education systems across the globe.

Over the past few decades, international policy makers have spent significant time and financial resources incrementally tweaking our existing education systems. This has been especially true in the United States where these tweaks have not been broad enough to outpace the economic and societal changes underway. Today, there is a clear and vocal consensus among all stakeholders that our model of schooling is not effectively preparing students for today, let alone for the challenges and opportunities of tomorrow.

Our model of schooling is indeed a vestige of an outdated system. But, we have not yet invented the models to which we can all say "yes." In order to close an achievement gap and prepare all students in our evolving societies for success in careers and the future challenges that await them, a radically different approach is needed. 


\section{Emerging Signs of Promise}

We are gaining a deeper understanding about the elements needed for schools to work more effectively. Research is beginning to amass evidence on correlates to student success in university and beyond. We now have reason to believe that learners do better in environments that go beyond core content knowledge, in which there is a focus on a set of essential skills and dispositions related to collaboration, communication, creativity and self-direction. School models that focus on these skills and dispositions often yield more successful students (Dymnicki et al. 2013; Chicago Research Consortium 2013).

Emerging work around personalization is showing some early cause for optimism on focusing on the unique needs of each student (Pane et al. 2015). While still developmental and lacking a significant research base, there is a growing movement of educators in the United States and internationally moving in the direction of thinking of the student as a unit of analysis and learning, rather than by cohort, class or grade level groupings. Related developments among educators and education policy in the US are moving toward more of a competency-based assessment model, or the idea of supporting students to move on when, but not until, ready. Here the focus is on the ability to demonstrate knowledge, understanding and skill acquisition in a deeper way. This calls into question the relevance of grade levels and many structures of school systems, including time and adult roles, thereby challenging the very firmament underpinning most school models.

We argue strongly that personalized and competency-based learning environments are not only critical for students, but that they are essential for educators to experience as part of their professional learning. We must fundamentally redesign our systems of pre-service and in-service training for educators. Both systems are currently modeled on an outdated system-one that is centered on the people who run the system, rather than the participants. This in turn treats these adult learners monolithically rather than individually, largely ignoring a significant and growing body of research about the science of cognition, as well as adult learning theory. These efforts also ignore a set of important trends affecting the education system more broadly.

Rather than the current focus on content and pedagogy exclusively in training, we need to provide a different kind of learner experience for our educators. This approach will have to build from their specific work 
environment, and the real problems they face in that context, rather than focus on concepts that are removed from their day-to-day experiences. If we can do that, we will make learning more relevant and, therefore, higher impact, tapping into factors that motivate more learning. The work needs to meet educators where they are as learners and allow them the flexibility to engage with content based on their readiness, rather than in lockstep with other colleagues who may have different needs or require a different pace. This type of personalized learning will be a better fit for adult learners individually. There is also the need to align credentialing to demonstrable evidence of shifted practice. This is how it will be competency-based. This approach holds significant promise because it models the kind of learning that we want for students. Therefore, the process itself, as well as the learning, has the potential to be transformational.

This process shift represents an approach that is more sustainable and promises greater wellbeing for adult learners as participants, and by extension for their students and the systems in which they work.

\section{Trends Impacting All Learners}

Context matters greatly. Before drilling down into understanding how our educators are currently trained, it is important to zoom out for a broader perspective because adult learners do not exist in a vacuum. Rather, they are significantly influenced by a set of outside trends, which impact them as individuals and as part of an evolving system of learning. Figure 7.2 illustrates a set of trends shaping the Future of Learning. Better understanding these trends can effectively influence how we shape a new system of educator training and learning.

These trends include:

- As Technology Evolves: What began around the turn of the twentyfirst century as electronic learning (e-learning) is evolving rapidly from strictly online learning to artificial intelligence, wearables and an accelerated movement toward technological singularity. While there is a clear continuum, the trend line is a significant one. On the e-learning end of the spectrum, content is now democratized in ways that we have never witnessed. We are seeing the emergence of a growing amount of free and open learning content (called open educational resources or OER), from curriculum to lesson plans to an array 


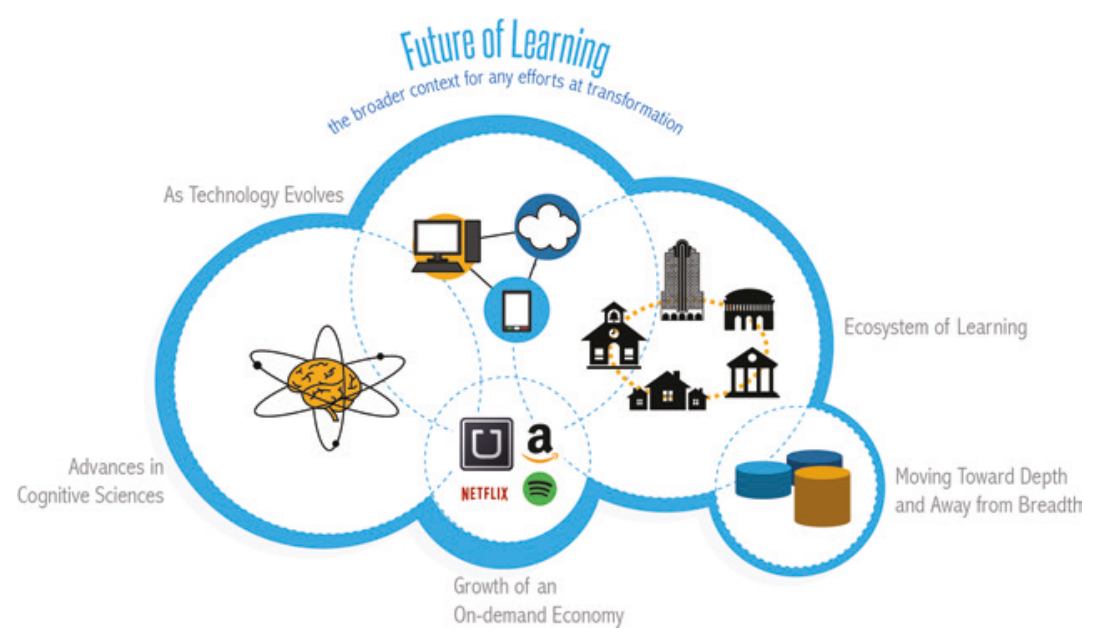

Fig. 7.2 Trends shaping the future of learning

of knowledge and skills acquisition opportunities, including Massive Open Online Courses (MOOCS), syllabi, books, etc. While it is still fragmented, an increasing number of efforts are underway to better taxonomize and organize this content. "Open internet tests" are on the rise in schools, as information is no longer the commodity itself; rather, the skill with which a learner can leverage and meaningfully apply content to demonstrate deeper understanding is what we increasingly care about. Artificial intelligence is still young but beginning to be leveraged to learn about students' interests, habits and patterns in order to push learning experiences based on those unique needs. Significant increases in capital investments in learning technology companies point to increased confidence and provides another indicator of the growing prominence of education technology. As illustrated in Fig. 7.3, these increases reached a high-water mark of over $\$ 2.6 \mathrm{~B}$ globally in the first half of 2015 , growing by over $50 \%$ from just a few years earlier (Adkins 2016).

What role should technology play as a way to better meet the needs of educators in their professional learning? We believe that there is an opportunity to think differently about time, space and pace for educator learning. We think it can be an important way of reaching these learners to access same and different content from one another, at same or 


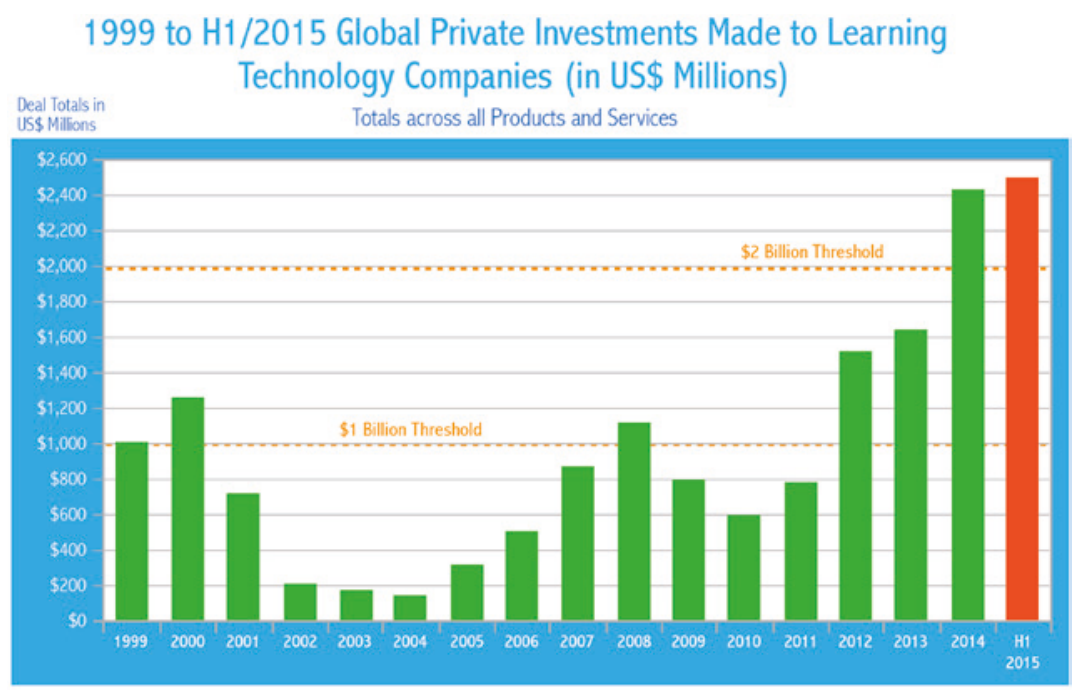

(Adapted by 2Revolutions from Adkins, 2016)

Fig. 7.3 Private investments in educational technology increase

different levels of complexity. Rather than "teach to the middle" the way most professional learning occurs, technology offers the opportunity to differentiate both content and the "dosage" of that content. While technology is an increasingly valuable tool, it is by no means the answer. Nevertheless, understanding and leveraging this trend represents an important chance to rethink the structures of educator learning.

- Advances in Cognitive Science: We know more now than we ever have before about how people learn, especially the intersection on the physiological, the pyscho-social and the impact of existing knowledge on learning (National Research Council 2000). These advances are informing curriculum and pedagogy, as well as the structure of school itself. For instance, our knowledge of neuroscience is encouraging educators to incorporate more movement and frequent breaks to maximize student learning. It is pushing structural changes in schools such as later start times in some high schools to account for student alertness; and fewer summer breaks because research shows the longer students are away from school, the more they forget. Adaptive software such as online content, learning games and online cognitive tutoring tools have emerged. This allows us to rethink how content is delivered 
within learning models and the role of adults in those models, all building from a deeper understanding of how different learners can engage with content and support systems.

Are there opportunities where these trends can help educators themselves learn differently? We believe that there are many ways to leverage adaptive software and different learning structures to promote greater engagement among educators and ultimately, better meet their unique needs and maximize their professional development.

- Growth of an On-Demand Economy: Technology and advances in cognitive science are being leveraged together to rapidly grow an on-demand economy for much of what we consume. We watch our movies on Netflix or Amazon Prime; we order our plane tickets on Orbitz or Google Flights; we book our vacations on Airbnb or VRBO; we now Uber or Lyft when we land in a city versus hailing a cab. All of these trends represent a significant shift in user behavior, placing goods and services at our fingertips, accessible through our laptops or smartphones. How is this trend beginning to inform education and shift how we learn? Crowdsourced lesson plan websites (i.e., Teachers Pay Teachers, Better Lesson, Share My Lesson, Curriki) are proliferating and free learning management systems (i.e., Google Rooms, Moodle, Blackboard Connect, Edmodo) are changing the landscape, providing not just learning platforms but content warehouses from which we can assemble learning experiences for students. We at 2 Revolutions are partnering with eleven other national organizations in the US to make online learning resources (diagnostics, playlists and courses) free and downloadable for use in other learning systems.

When you look at the enormous size of investment in professional learning, with recent estimates suggesting the United States annually spends more than $\$ 400$ billion on formal and informal training by employers (Matlach and Poda 2016), we strongly believe that educator learning is soon to emerge as more of a market opportunity in the on-demand economy. Aggregating demand for content (subject matter specific, related to pedagogical skills and practices, micro-credentials, etc.), as well as targeted on-demand expert supports ("ask a question", virtual coaching, etc.) represent learning experiences certain to shift the landscape. The model that we outline for the future of educator learning makes significant use of both the demand for content and on-demand expert supports.

- Moving Toward Depth and Away from Breadth: Learning more about single topics, and doing more with that content, is a decided 
shift in classroom learning. Over the past few years in the United States, there has been a move to a set of common and more rigorous standards across many states- the Common Core Standards. We see a growing number of efforts that are asking students to work deeper, as evidenced by the focus on greater depth and thinking skills on new high stakes exams within K-12, such as PARCC and Smarter Balanced efforts. In the US state of New Hampshire, a groundbreaking initiative has garnered a waiver from the US Department of Education and is currently being emulated by other American states. The Performance Assessment for Competency Education (PACE) initiative leverages a federal waiver to allow a small number of school districts to replace high stakes exams with high quality performance assessments calibrated across multiple districts for reliability. These efforts and a broader push toward deeper learning have raised questions about breadth versus depth. In a growing set of school models, there is a shift underway to think differently about what students learn and how they learn it. Portfolio defences or learning expositions are accelerating as a way to measure student learning in ways that require the demonstration of knowledge and skills, and increasingly, the ability to apply that learning to a real world context.

As we rethink educator learning, we are confident that this trend will influence both the content and process by which educators are trained, with an emphasis on going deeper in their learning versus broader to cover more topics. This shift will push our educator learning models toward fewer priorities, a more substantive treatment of those priority areas, and intentional ways in which key priorities—such as content knowledge and twenty-first century skills and dispositions — can be thoughtfully integrated in curriculum and instruction. It will begin to question notions of seat time (attending sessions and getting credit for attendance alone) in favor of building an evidence base by which to substantiate one's individual learning.

- Ecosystem of Learning: Within the past hundred years, learning was thought to be centered on the school building-kids learned between 9 a.m.-3 p.m. However, this is beginning to shift, as evidenced by new and different ways of thinking about and promoting a student's learning trajectory. Middle class and wealthy families have historically supplemented their children's school learning with enriching extra-curricular learning in the afternoons, evenings and weekends spanning sports, the arts, the world of work and other interest areas. Given the breadth and depth of this extra-curricular learning, and the 
impact it has on the student's overall knowledge, skills and dispositions, there is a growing movement to think differently about education versus learning. The school building used to have the market cornered on learning, and it was assumed that it was where someone "got educated." Now, there is a blurring of the lines between formal and informal learning. In the US state of Nevada, policy was passed within the past few years where $90 \%$ of the learners per pupil allocation go directly to the family to determine how they might spend it, rather than $100 \%$ going directly to the school district, as is the case in most places now. That raises all kinds of questions around how we think about learning. In the US state of Colorado, an initiative called ReSchool is asking different questions about life paths and learning, with a set of emergent prototypes testing how informal learning could supplement or replace formal learning environments like school. Over the past five years, the MacArthur Foundation has grown an initiative called the Hive Learning Network. The Hive attempted to formally network informal learning among non-profit organizations and businesses focused on the arts, youth development and entrepreneurship. Over time, this expanded from Chicago and NYC to a set of cities around the world. It has continued to grow into a relatively new initiative, LRNG, across 12 American cities, with a focus on interest-driven learning that is available anytime/anyplace through an online platform. Another notable component of the work is what LRNG calls verifiable and credible learning through badges that have currency at school and in the workplace.

This move toward a broader ecosystem of learning is another important trend that will begin to impact educator learning. For too long, professional development has been a monolithic domain, where learning was slated to happen during a few annual in-service days and at district-wide professional learning sessions. Now, learning is moving toward interest and need-driven, and will increasingly be democratized as anytime, anywhere. We are closely watching how educator learning can tap into the intrinsic and extrinsic motivations of adult learners alongside a growing range of more flexible currencies that are being developed to verify and credit educator learning experiences, from continuing education credits to badges, graduate credits, and master teacher status through an array of micro-credentials.

Each of these trends not only provides us with a broader context, but also are, of themselves, important data points. As we consider the 
educators within our systems, these external forces are impacting them personally and professionally. We need to be aware of their potential and seek to leverage these trends to positively impact how educators learn. The approach we are building and testing leans heavily on these trends because we strongly believe that they are already having noticeable impact, not only on educators but on the future system of learning.

\section{Why Teachers are the Critical Element}

While learning can and should occur broadly, school remains a primary interface of learning for most students. Schools are very complex systems. When we dissect schools, there are a set of component parts that need to work together to optimize the learning for students. Figure 7.4 below provides an illustration of a set of levers needed to design and implement effective learning models.

As an organization, 2Revolutions has helped support the development of a substantial number of new and transformed school models over the years. While each school model lever is important to the success of a student's learning experience, educators are the common denominator and, along with school leadership, are driving most of these design levers

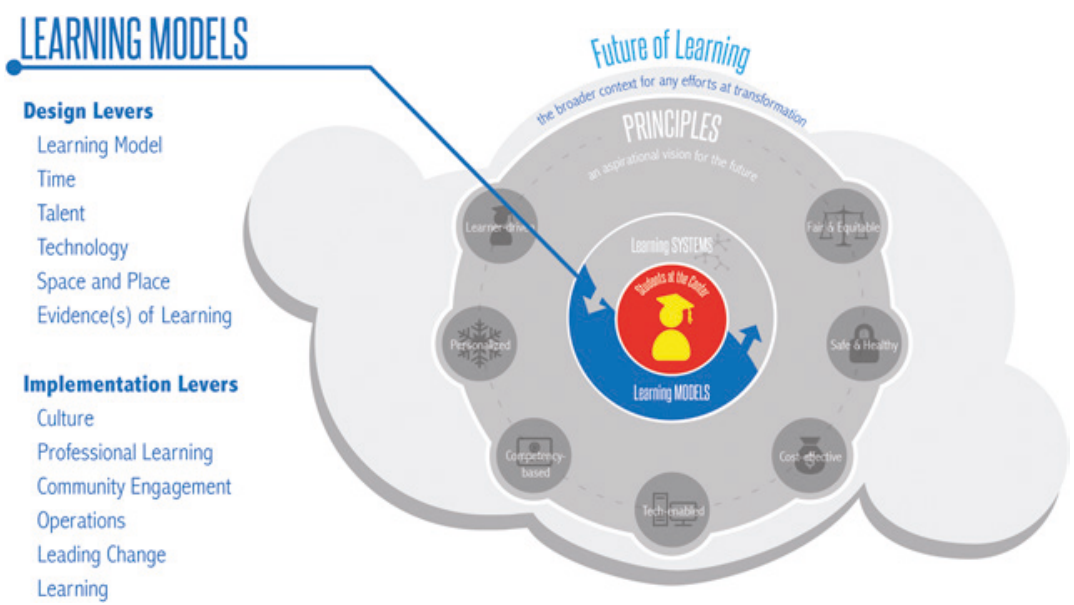

Fig. 7.4 Future of learning design and implementation levers 
(learning model, time, talent, technology, space and place, evidence of learning), and deeply participating in-if not driving-all of the implementation levers.

There is a very strong research base squarely pointing to the efficacy of teachers as one of the biggest drivers of student success. A study by the RAND Corporation (2012) on measuring teacher effectiveness found that the biggest school-related factors to student achievement are teachers. We know that the relationships between students and teachers are important drivers for student success (Schieb and Karabenick 2011), and that students' life outcomes, as measured by earning potential, are directly impacted by the quality of their teachers (Hanushek 2011). In fact, the effects of teachers on student learning are not only quite high but are also cumulative and long-lasting. The effects of just one teacher can impact a student's future learning for up to four years (McCaffrey et al. 2003), and potentially even after graduating: when students are taught by high quality teachers, they are more likely to attend college, have higher salaries upon entering the workforce, and save more for retirement (Chetty et al. 2011). Student success, in effect, is highly dependent upon effective educators both in and outside the classroom.

How do we maximize the value of effective educators? What can we do as a system to increase and sustain the quantity of high quality educators? In order to impact learning, at scale, our educators need an improved approach to training and support. It is these adult learners who, when engaged, empowered and supported to learn differently, can leverage that experience to drive real and lasting transformation of student learning. In the aggregate, this represents a significant opportunity for systemic impact.

So, where to invest-pre-service or in-service training? We often find ourselves needing to choose because of resource limitations, regulatory trade-offs or because of what is within our control from our seat within the system. We would argue that it is a false choice. Transformation of both initial teacher education and in-service training are desperately needed. The remainder of this chapter is focused on rethinking in-service training, which we are confident offers some pedagogic and design ideas concepts to transform initial teacher education. 


\section{An InNovator's GPS: SEeking a Solution}

In order to transform our current systems, we need a framework for finding our way. This framework provides us with a means to situate where we are versus where we are trying to go. The image in Fig. 7.5 illustrates the shift we propose to take. Make no mistake that most organizations exist squarely in the Now-our current reality is limited and has diminishing returns. It was created and perpetuated as much by the confines of the regulatory environment as by an array of cultural norms around what professional development was meant to do and how it works for some adults in the system. Meanwhile, we do not have aggregated and well-organized demand for a new and better approach to educator training. We need to understand the limitations of our current situation in order to chart a clear course for the Future. This Future represents spaces ripe for the development of innovations, unburdened by the current systems' limitations. Once we document our Now and concretely outline the Future, the Next is the necessary bridge to help us leap the chasm between here and there. As we outline in this chapter, we build the bridge to the Next atop a core set of design principles. Crossing the chasm to the future is difficult, but the iterative process of learnexperiment-prototype helps us achieve a culture of innovation required for transformation.

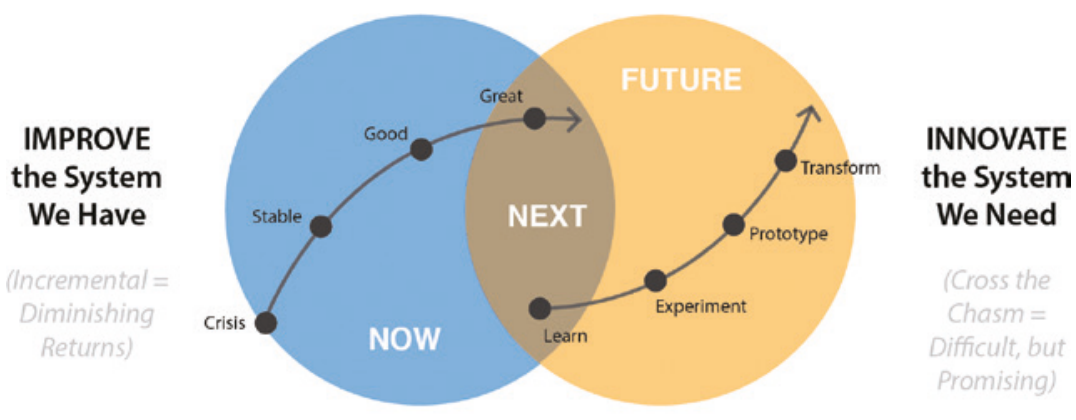

2 Revoluti $\oplus$ ns

Fig. 7.5 Innovator's GPS improvement to innovation 


\begin{tabular}{lll}
\hline Now & Next & Future \\
\hline $\begin{array}{l}\text { PD is largely passive, } \\
\text { inefficient, isolated, and } \\
\text { stagnant }\end{array}$ & $\begin{array}{c}\text { Adult Learning that is } \\
\text { personalized, compe- }\end{array}$ & $\begin{array}{c}\text { Better outcomes for stu- } \\
\text { dents; sustainability and }\end{array}$ \\
& $\begin{array}{l}\text { tency-based, modular, } \\
\text { motivating, relevant, } \\
\text { respectful, collaborative, } \\
\text { and sustainable }\end{array}$ & teachers and systems \\
&
\end{tabular}

\section{Now}

We should seek to be fellow students with the pupil, and should learn of, as well as with him, if we would be most helpful to him.

—Henry David Thoreau

Today's approach to professional development for teachers is troubled by many of the complex challenges facing our broader education systems. While there is a great deal about the system that is improving, we would contend that there is much about the current system of educator professional learning that is not working. It is clear that we are spending a tremendous amount of resource on professional learning, with questionable outputs and outcomes. By naming and better understanding these elements, we have an opportunity to make the transition to the future we seek.

In this section, we examine some limitations within the current professional development system related to effectiveness, sustainability, and well-being.

\section{EFFECTIVENESS}

While research has already identified what it takes for educator learning to be truly effective, our current situation is a far different reality. The ways in which we currently support educator learning are constrained by significant structural challenges to efficacy. These challenges can be divided into several core problem streams: learning is passive, time is being used in questionable ways, the work is isolated from the needs of educators, and there is an overall stagnancy to much of the training. All of these taken together highlight this cycle of inefficacy. 
Learning is Passive: Currently, one of the greatest barriers to effective educator learning is its inherent passivity. In fact, fewer than one in three teachers can choose most or all of their professional learning opportunities, while nearly one in five teachers never have any say in their professional development (BCG 2014). Both pre-service and in-service development often tends to default to the quantity of seat time rather than the quality of active, relevant and job-embedded learning (Dunne 2002). This "one-size-fits-all" approach perpetuates a system of ineffective educator learning. Fewer than one in three teachers choose most or all of their professional learning opportunities. Nearly, one in five never has a say in their professional development (BCG 2014).

Inefficient Use of Time: Even if the quality of the initial experience is high, educator learning is still frequently inefficient because of the limited time dedicated to improving practice. It takes on average 20 separate instances for a teacher to master a new skill (Joyce and Showers 2002), yet a recent report revealed that American teachers receive limited support and lack sufficient time to deeply engage in more effective instructional strategies (Gulamhussein 2013).

Isolated: A report by the Boston Consulting Group (2014) for the Gates Foundation, in which over 1300 teachers were surveyed, found that the large majority of educators do not believe that the professional development they receive is helping them prepare for the changing nature of their work as twenty-first century educators. Educator learning was found to be most lacking around effective use of technology and digital learning tools, accurate analysis of student data for differentiated instruction, and aligned implementation of the Common Core State Standards. However, subject matter is not the only element isolated from their training: current educator learning also lacks collaborative connections to other educators. Over half of all American teachers have never observed a colleague's teaching (OECD 2014). Without a collaborative, context-based focus in educator learning, significant change in teachers' practice will not occur (Sturko and Gregson 2009).

Stagnant. A variety of surveys and reports on American educator learning uncovered a systematic network of discontent. Only $29 \%$ 
of teachers surveyed were highly satisfied with current professional development offerings, and only $34 \%$ felt the system of professional development has improved over past iterations (BCG 2014). This dissatisfaction is further substantiated by the fact that the results of educator learning have largely stagnated. For many teachers, professional growth tends to plateau after only the fifth year of teaching; in fact, the difference in evaluation ratings between an average firstyear teacher and an average fifth-year teacher was more than nine times the difference between a teacher in her fifth year and a teacher in his twentieth (TNTP 2015). This pervasive culture of low expectations for teacher development and performance prevents educator learning from becoming truly effective.

Additionally, it is important to examine the current range of approaches used in educator training, to understand the perspectives of both teachers and district leadership. In Fig. 7.6, we pull data from the Boston

\section{Significant Disconnects}

While districts focus on coaching, lesson observation, and professional learning communities, teachers are not satisfied with their implementation to date

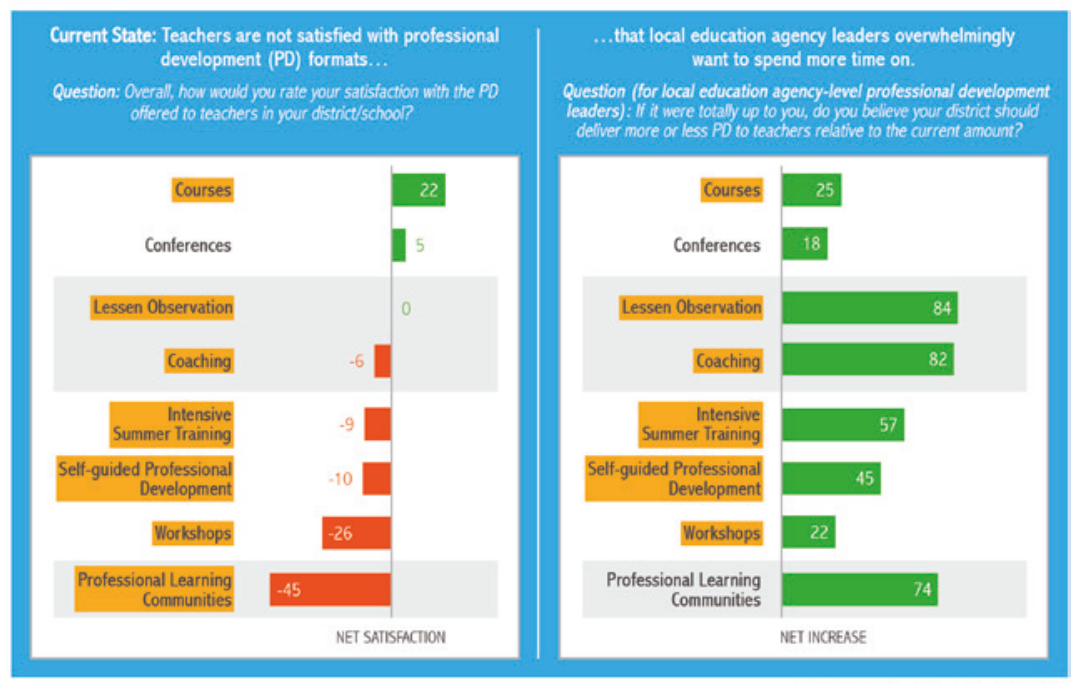

(Adapted by 2Revolutions from BCG, 2014)

Fig. 7.6 Perspectives on professional learning component parts 
Consulting Group study as evidence of educator opinion, as well as a way of examining specific disconnects between the opinions of teachers and system-level decision makers.

In environments where we are working deeply in partnership with state education agencies, school districts and charter management organizations, there is often a lack of coherence between and among professional learning offerings, which creates a significant disconnect for the educators and contributes to the lack of efficacy in the training. All of these data point to a missed opportunity for impact with the educators.

\section{Sustainability}

When we consider the importance of this work, the potential for impact and current expenditures against the need, there is a tremendous disconnect, especially when one considers the hefty resources-both in time and money-expended for educator learning.

- Professional development is big business. In 2014, approximately USD $8 \mathrm{~B}$ was spent on professional development in the 50 largest districts within the US alone (TNTP 2015). Estimates range, but some put the annual costs of K-12 professional learning in the US at USD 18B/year (BCG 2014).

- A typical teacher spends 68 hours each year-more than a week and a half-on professional learning activities typically directed by districts. When self-guided professional learning and courses are included, the annual total comes to 89 hours (BCG 2014).

- High quality, personalized professional development, such as a mentoring program, is linked to increased teacher retention (Darling-Hammond et al. 2009). When teachers feel that they have opportunities for growth, their sense of efficacy and competency increases, making them more motivated to remain in their current position (Huang and Cho 2010).

Given the return on investment demonstrated by the data detailed above, questions about the current system persist and deepen. But beyond the direct impact on student learning, these expenditures also raise questions about broader issues of sustainability. Are we growing and retaining a future-ready workforce? Are we not only developing the individuals themselves, but also being mindful of the rapid developments 
in the field and the need for these professionals to stay relevant amidst tremendous change, as the work and the context in which the work happens (e.g., rapidly evolving student populations) continues to shift?

Around the world, there have been breakthroughs in educator learning in many high-performing countries, shown by the rates at which greater teacher satisfaction and efficacy are frequently correlated to higher levels of student achievement (OECD 2014). Nevertheless, these systems of professional learning are still a work in progress, based on self-reports and external analysis, particularly in high-needs schools across the globe. Additionally, educators in a diverse range of countries often highlight a "support gap" (OECD 2014) in their collaborative professional development, demonstrating significant room for growth that could well benefit from real innovations in educator learning.

In order to transition from the current state to the Future, and for our system of professional learning to work better at scale, there is the need to empower teachers as owners of their learning while acknowledging that the school principal and district leadership have necessary responsibilities and important perspectives that need to be taken into account.

\section{Next: Crossing the Chasm}

What I hear I forget, what I see I remember, what I do I know

-Xunzi

How do we cross the chasm between Now and Future?

There is a bridge, built upon a set of core design principles, informed by a set of theoretical frameworks around learning. These frameworks focus on the development of skills, knowledge, and dispositions, respectively. When we think about these frameworks and leverage them in a more integrative fashion, rather than in isolation from one another, we substantiate the argument for and the feasibility of the approach outlined for educator learning in the Future (Fig. 7.7).

Picking up on clear themes from the Now, we begin with the premise that educators are largely underserved by the value of the learning opportunities available to them. This is a point about the process and structure of the learning. While we also take issue with the content, which often is perpetuating more traditional approaches to instruction and assessment that are less effective with growing populations of more 
Fig. 7.7 Crossing the chasm to the future

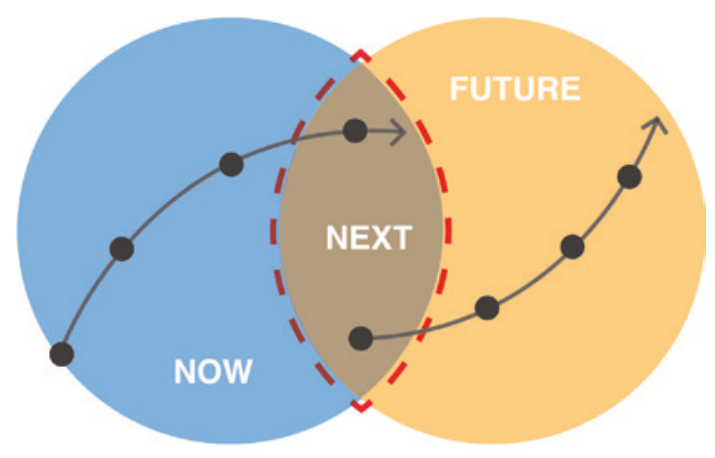

2Revoluti@ns

diverse learners, in the context of this chapter, we strongly believe that by addressing structural challenges around the process of educator learning, we can yield real shifts for students, teachers and systems.

In this section, we outline a set of constructs for skill, knowledge and disposition development. In the Now, a limitation that we identified is that we start with skill development or knowledge development as a point of entry for educator learning. Taken by themselves, these are good but insufficient for the Future we seek. Rather, there is the need to more effectively integrate these points of entry; we need a more intentional and significant approach that is about knowledge, skill, and disposition development. It is through this approach that we will be able to span the breadth and depth of the chasm, in order to support a transition to the Future.

The professional learning system itself can and should serve as the induction into a new way of teaching and learning, by engaging educators in experiences that model innovative and integrative approaches to teaching and learning. This new system begins with dispositions as foundational and builds knowledge and skills atop those dispositions.

Much emphasis has been placed on knowledge development in education writ large. There is common agreement among educators and researchers that the ability to flexibly transfer conceptual understanding to various real-world situations is the hallmark of knowledge (Wiggins and McTighe 2005). Expanding on Bloom's Taxonomy, Webb's Depth 
of Knowledge enables us to calculate cognitive depth by categorizing learning tasks across four levels of cognitive demand: recall and reproduction, skills and concepts, strategic thinking, and abstract thinking (Webb 1997). While knowledge is indispensable to the educator's professional learning, it is insufficient in shifting practice. The development of educator skill must also be prioritized.

There has been much recent emphasis on deeper learning competencies, such as Michael Fullan's "6 C's" as part of the New Pedagogies for Deeper Learning (Fullan and Langworthy 2014). The Center for Innovation in Education introduced research-based developmental progressions for collaboration, communication, creativity, and self-direction in the Essential Skills and Dispositions Framework (Lench et al. 2015). Teaching methodologies such as a project-based learning at High Tech High, New Tech Networks, and Big Picture Learning have gained great traction among educators, but questions remain about how to ensure that content and skill are adequately developed alongside deeper learning competencies. Moreover, effectively supporting educators in implementing methodologies such as these, when many educators themselves have not experienced learning this way remains a critical question. Beyond these questions remains a larger one: what is the impetus for educators to significantly shift their practice when so much remains unknown?

Research on growth mindset and human motivation underscores the essential role of dispositions in learning and development. Carol Dweck's distinction between a growth and fixed mindset reveals how influential our own views on intelligence and talent are on our potential for continued learning (Dweck 2007). Daniel Pink's research reveals how influential autonomy, mastery, and purpose are in motivating us and points the way beyond traditional rewards and punishments to achieve the highest human potential (Pink 2009). John Hattie's Eight Mind Frames contextualize growth mindset within education and specify particular educator dispositions that correlate to the most positive impact on student learning (Hattie 2012).

In order to make a shift, we advocate a different approach to professional learning-one that begins from the perspective that educators have a unique set of needs. They are first and foremost adult learners; therefore, they both learn differently and require an approach that honors and builds from their life and work experiences. Rather than treat them monolithically, there is the need to acknowledge that they have different needs and are on a continuum in their knowledge and skill development. 
Thus, there is the need to establish a different way to support them and their learning.

This approach is one that should be more grounded in andragogy (from the Greek andra meaning "adult" and agogus meaning "leader of") versus pedagogy (from the Greek paid meaning "child" and agogus meaning "leader of"). Malcolm Knowles (1992) asserts the logic that adult learners have a fundamentally different set of needs, and therefore, pedagogy as a driving assumption for educator learning misses the mark. In Fig. 7.8, Knowles offers a comparison between andragogy and pedagogy.

In this context, comparing pedagogy and andragogy raises real questions as to how our future system of educator learning ought to work. It also forces us to reflect on what kind of professional will better meet the quickly evolving tasks at hand. In the current system, research illustrates that professional learning is often more passive, compliance-oriented, and extrinsically motivated. Reframing the learning opportunities through a lens of andragogy provides a new and different way to structure and support learning opportunities for our educators, first and foremost beginning from the premise that they are adults with a rich set of knowledge and experiences.

Do we want our educators to be dependent or self-directed learners? Do we want them to be a repository of information or generative learners leveraging their own experiences to deepen students' knowledge and understanding? What role do their own problems of practice play in their learning versus theoretical constructs too often disconnected from real needs they have in their classrooms?

\begin{tabular}{|l|l|l|}
\hline \multicolumn{1}{|c|}{ ABOUT } & \multicolumn{1}{|c|}{ Assumptions } \\
\hline Concept of the learner & Dependent personality & ANDRAGOGICAL \\
\hline Role of the learner's experience & To be built on more than used as a resource & A rich resource for learning by self and others \\
\hline Readiness to learn & Uniform by age-level \& curriculum & Develops from life tasks \& problems \\
\hline Orientation to learning & Subject-centered & Task- or problem-centered \\
\hline Motivation & By external rewards and punishment & By internal incentives and curiosity \\
\hline
\end{tabular}

Fig. 7.8 Pedagogic vs. andragogic assumptions 
We would strongly contend that the kind of educator we want maps clearly to the kind of system of learning we now need for students. As economies shift and demands on the labor market change with greater frequency, our societies need learners to be more versatile, evolving from a focus on a certain type of content knowledge to a set of transferable dispositions and skills. Content knowledge matters, especially at a foundational level for students, but as a student matures, that content is more accessible today than ever before through a wide range of accessible sources. Understanding what you need, where to find it, and how to apply it is far more valuable in our knowledge economy than being a knowledge repository in and of itself. Therefore, these shifts clearly need to help guide our system of professional learning for educators.

If we prepare and improve our educator learners through a new and different approach that privileges the individual and moves toward demonstrable learning versus seat time, by virtue of their training, we are likely to imprint them with a more nimble and responsive model for their teaching. Therefore, the import of educator learning is multi-fold-it has direct impact on learners and it builds a more successful and sustainable model for the educator learners, all of which contributes to greater educator wellbeing.

As we consider a more integrative approach that blends knowledge, skills, and dispositions, an evolved system of educator learning emerges. This new approach requires a set of guiding design principles, supported by the theoretical research base outlined in this section. It is these principles that provide the bulwark from which we can build a more effective system of educator learning. Moving forward, we believe that professional learning should be:

- Personalized: Targets the unique needs of each educator within their practice rather than one-size-fits-all professional learning.

- Competency-based: Begins by establishing an understanding of what educators know and can do rather than teaching to the middle. It also advances an educator in their learning based on demonstrable mastery of content, as evidenced by shifted practice within the classroom. Mastery correlates to achievement, which represents a departure from professional learning based on seat time.

- Modular, not Monolithic: Breaks the complexity of learning into a set of component modules. This allows for personal focus on areas of need or interest rather than a broader topic in which the 
educator may have already mastered some of the content or their context may have shifted and the additional content is no longer relevant.

- Motivating: Acknowledges the need for intrinsic and extrinsic motivation for participants, that there is clear encouragement for educators to want to learn. The motivations extend beyond a shortterm compliance exercise, clearly linked into the career pathway, whether this incorporates badges, graduate credits or a focus on mastery with an opportunity for different job responsibilities.

- Relevant. Meaningfully aligns with school- and district-wide efforts rather than a set of learning activities disconnected from one's direct areas of focus (classroom and/or school). This ensures that the professional learning is an integral part of the work at hand rather than something that is external and, therefore, not directly relevant.

- Respectful: Treats people like professionals by honoring the expertise they bring, their unique context, and their learning style. It gives people choice in what they do anchored to interest and need, when they do it, and how they are assessed. All of this can yield significant improvements in both efficacy of the work and satisfaction with the process.

- Collaborative: Leverages the power of groups as appropriate to push one's thinking, promote learning together, and benefit from different skill sets and dispositions. Collaborative professional learning is as much about the individual as the collective. Additionally, because of the power of technology, there are opportunities that can happen to facilitate collaborations across a school building, around a district or across broader areas.

- Sustainable: Significant amounts of money are spent on professional development in most systems. There should be attention paid to the outcomes and how it contributes to professional growth as evidenced by student outcomes, teacher retention, teacher satisfaction, and wellbeing.

These principles must be informed by the research but anchored in a local, contextualized vision for student learning. Local context matters deeply and should be the driver for the construction of the Next. 


\section{FUTURE}

Every person of learning is finally his own teacher.

—Thomas Paine

Imagine a scenario in which each adult learner was respected as a professional, met where they are in their learning journey, and supported from that place to further stages of their development. This scenario mirrors the kind of learning we want our students to experience: learning that is personalized, relevant, and geared to students' current levels of learning, while pushing them to their learning edge. In Fig. 7.9, we provide a framework for this future-oriented process in which educators experience a new kind of learning.

The approach, outlined above and detailed in the following section, represents a way to realize this vision, with the clear belief that educators need to experience learning in a way that intentionally integrates the

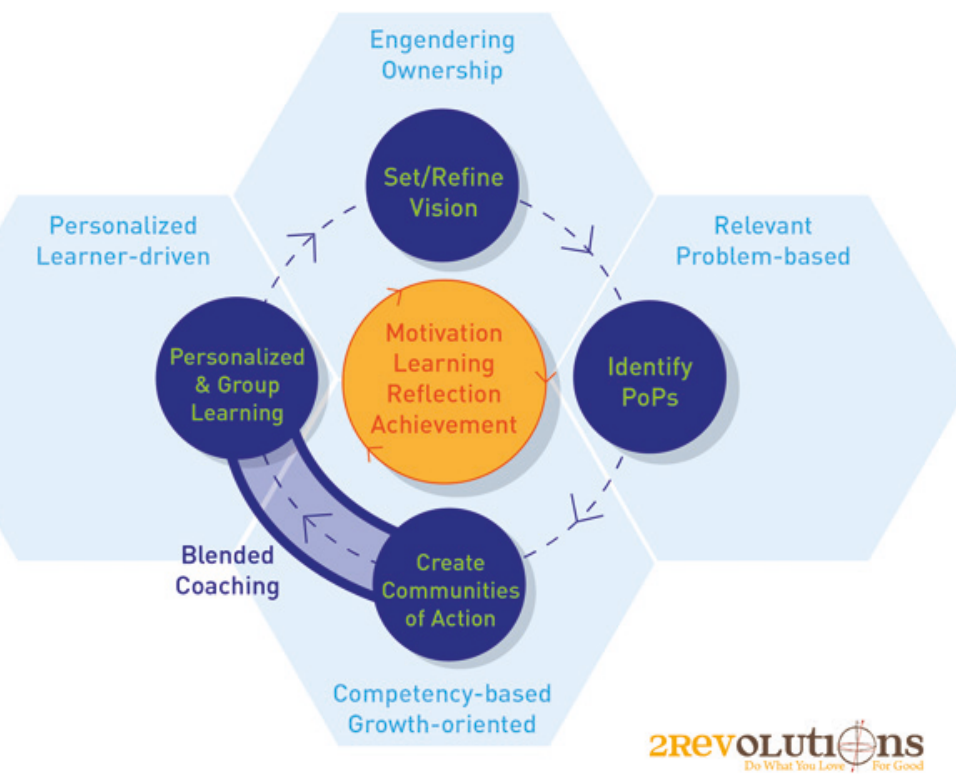

Fig. 7.9 Anchoring in adult learning theory 
knowledge, skills, and dispositions they need to be effective and grow their prowess as practitioners.

There are clear stages of this learning process. While made up of distinct elements, for this to work over time, the essence of the work is integrative, not linear. In this section, we will detail the following stages: Engendering Ownership; Personalized Learning; Competency-Based Learning; and Shifting Beliefs.

\section{Engendering Ownership}

Most educators are drawn to their work by a mission to help students learn, which is a significant intrinsic motivator. Educator learning is motivated by mission, but amidst the real and persistent challenges of the work, there is the need to maintain and deepen this motivation over time. The importance of motivational psychology is vital to the learning process. Simply put, if there is no motivation to learn, then there is no learning (Walberg and Uguroglu 1980). There is a real need to engender ownership in the learning process. Educators who feel included and in control of their learning are more likely to be involved and active in their development (Wlodkowski 2008) — thus building educator agency is critical to the long-term success of the effort. This is further underscored by Knowles' work on andragogy detailed earlier in the chapter and evidence of greater success in the classroom when teachers reported having more agency in their learning (BCG 2014).

To do this work effectively requires an authentic process whereby educator voice is meaningfully engaged to help inform their learning, as well as more broadly shape the context in which they work. This approach helps to make their learning feel relevant to them.

A few key activities in this phase include:

- Visioning: It is important to lead with invitation rather than edict. Educators all work within an existing context, which has a culture and a set of expectations, norms, and pathologies. Rather than divorce these from the learning, which happens far too often, there is the need to anchor the work within that culture, so as to better understand it and position learning within it, which will help promote real sustainability in the work itself. Key elements of visioning include: 
- Student attributes: What are the key attributes (knowledge, skills and dispositions) of successful learners upon completion of their learning at your school?

- Learning principles: In order for students to embody these attributes, what needs to be true about your learning environment and the qualities of the student learning experience? What are words that capture these characteristics?

- Barriers: What are obstacles that are getting in the way for you in realizing this vision for learning at your school?

This activity provides an opportunity to be clearer as a team about the direction you want for your school, anchored in a co-constructed idea of what student success looks like. Figure 7.10 provides an illustration of one school's vision. The vision serves many purposes. It acts as a guidepost by setting a clear target at which to aim. It models communication and collaboration in action. It also provides a tangible opportunity for educators to help inform the outcome of their work more broadly, spurring selfdirection, and empowering them as drivers of their work-rather than passive vessels who only carry out directives without the ability to shape them.

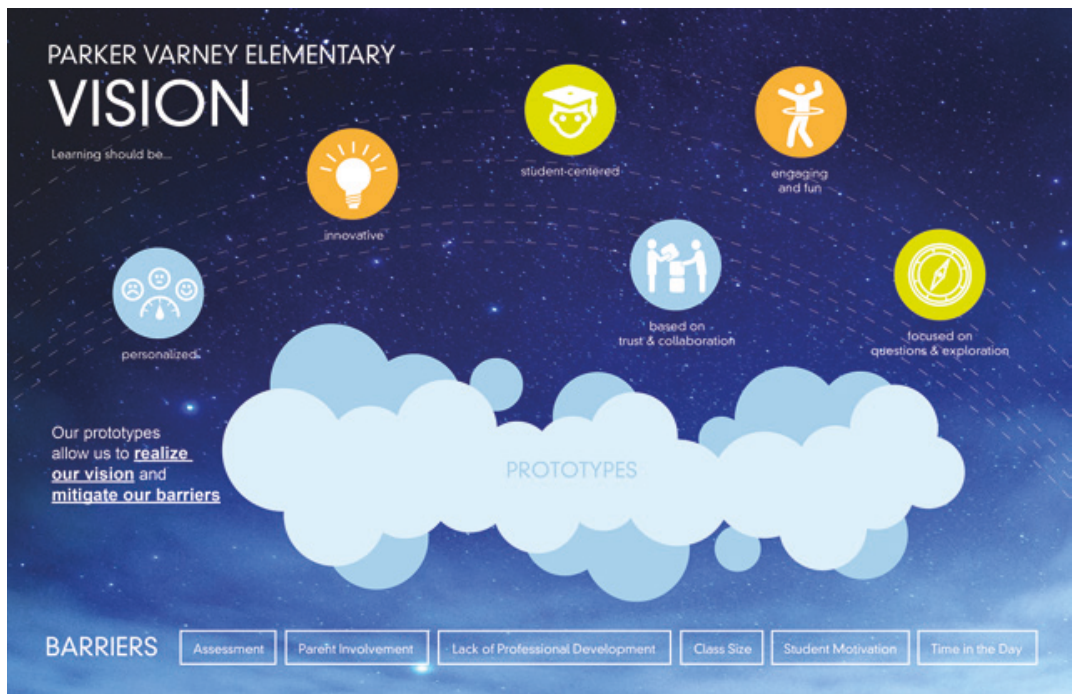

Fig. 7.10 School vision artifact 
All learning is contextual and personal. By inviting educators to inform their environment, there is an opportunity to anchor their professional learning against the mission of their work, thereby activating and orienting their disposition toward continued learning and development.

- Problems of Practice: Out of the visioning process comes a clear sense of barriers. These self-reported challenges are analyzed and discussed. What is preventing the realization of the vision-at the level of individual and the collective? That which emerges here helps drive the development of problems of practice. These problems translate into demand-driven, relevant learning opportunities, aligned with the unique needs of the individual and/or groups of teachers. There is the need to evaluate problems and validate them as credible and pressing barriers to student learning; building on Harvard's Instructional Rounds, it is important to leverage peer and leader feedback to ensure problems of practice meet a core set of criteria reflected in Fig. 7.11 (City et al. 2009).

- Communities of Action: A set of clear trends emerge from the analysis yielding common problems of practice. Around these common problems, there is an opportunity to form action-oriented educator collaborations whereby teams work together to learn by

\begin{tabular}{|c|}
\hline $\begin{array}{l}\text { Draft Problem (s) of Practice } \\
\text { Now combine your personal interests/aspirations with the priorities and/or barriers you just identified to } \\
\text { draft one or more (but no more than 3) problems of practice to focus your continued learning. }\end{array}$ \\
\hline $\begin{array}{l}\text { HOW CAN I INCREASE STUDENT INTRINSIC MOTIVATION, AS EVIDENCED BY INCREASED } \\
\text { ENGAGEMENT IN LEARNING TASKS AND PERSISTENCE IN THE FACE OF CHALLENGE? }\end{array}$ \\
\hline $\begin{array}{l}\text { Refined Problem (s) of Practice } \\
\text { Now review your draft problem(s) of practice against the following criteria. Ideally, gather feedback } \\
\text { from at least one other colleague or coach as well. }\end{array}$ \\
\hline $\begin{array}{l}\text { - Relevant: Related to work you're already doing or something you need to work on } \\
\text { - Connected: Has a connection to the larger school vision and priorities } \\
\text { - Central: Focused on the instructional core - the interactions between the teacher, students, and content } \\
\text { - Actionable: Specific, time-bound, and controllable enough for you to take on } \\
\text { - Observable: Grounded in some kind of evidence so you can see improvement and share results } \\
\text { - High-Leverage: If you can act on the problem, it would make a significant difference for student learning }\end{array}$ \\
\hline
\end{tabular}

Fig. 7.11 Problem of practice artifact 
doing. These communities of action, akin to more traditional professional learning communities, are time-limited and anchored in an improvement science methodology of short-cycle prototypingaddressing a clear problem of practice, with a hypothesis to be tested and a course of action that by design, is meant to quickly test, learn, and refine in order to improve practice. Through this process, educators come face to face with knowledge and skills gaps. Figure 7.12 illustrates an example of the short-cycle prototyping process that 2 Revolutions uses to support teams in problem solving within a Communities of Action context.

\section{Personalized Learning}

Once we have identified areas of need, a set of topics will emerge as areas of focus for the Communities of Action. Before teams can dive into testing approaches, there is the need to build knowledge and skills. This is where personalized learning meets individuals and teams.

Each learner establishes a Personal Learning Plan that captures their unique needs, grounding the learning experience in their background, interests, working/learning style, and an inventory of their dispositions. With a better picture of the learner, we have an improved chance of meeting educators' needs and fueling their intrinsic motivations to learn.

Individualized coaching provides each participating educator with someone to help them manage their learning plan and provide ongoing feedback and validation of their learning. The coach role is intended to provide consistent supports to aid educators in achieving their personal learning goals. Coaches challenge educators to embrace and manage the

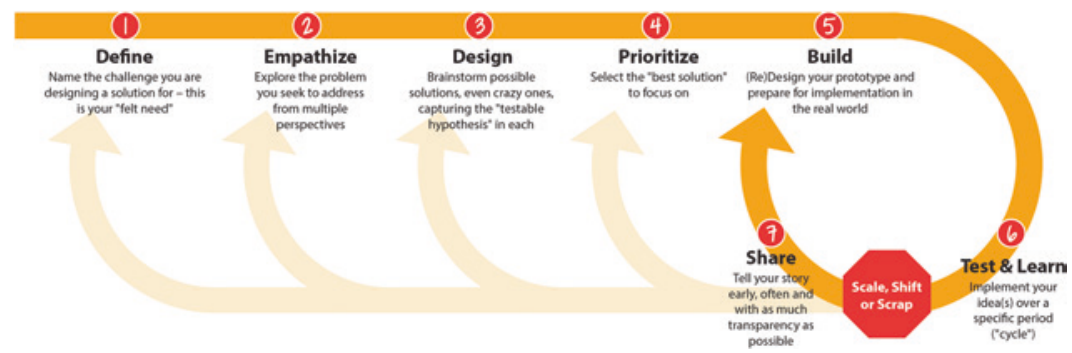

Fig. 7.12 2Revolutions' short-cycle prototyping process 
moments of discomfort that naturally occur in the change process and establish the relationships necessary to support educators at the edge of their learning. Based on their detailed knowledge of each adult learner, coaches orchestrate a variety of supports based on their coachees' specific learning needs. Coaching supports can come in the form of access to relevant learning resources, modeling, co-planning, co-teaching, observation and feedback, and more. Designated coaches need not serve as the sole provider of professional supports to their coachees; technologyenabled on-demand learning can and should be leveraged in service of learners. As long as adult learners experience a coherent continuum of supports anchored in their personalized learning needs and there is clear communication across all providers in alignment with these needs, expertise can be channeled from multiple sources.

A continuum of topical adult learning progressions meets the learner where they are and asks them to self-assess their current abilities across a continuum of performance indicators from Invested to Developing, Leading and Innovating. See Fig. 7.13 for an artifact of an adult learning progression around Tech-enabled Learning. Once the learner self-assesses, they can access topical playlists aligned to relevant learning progressions. These playlists provide leveled learning resources that learners can read, watch, or listen to in order to increase investment in various competencies and build relevant knowledge and skills. In a wide-ranging partnership, we have just recently released a compendium of high quality, free educator learning resources accessible through https://getinspired.2revolutions.net/external/signup.

All of these approaches are personalized because they work within the context of the unique educator, allowing them to work on content relevant to their work and taking into account their prior knowledge when providing opportunities for knowledge and skill development. Each educator is able to access the content most relevant to them and move at a pace aligned with their learning needs and style.

\section{COMPETENCY-BASEd LEARNING}

Making the shift from knowledge to skill development requires authentic demonstrations of learning in practice. Understanding a map of the competencies and the continuum or progression on which those competencies exist developmentally is critical. While there are a number of high quality sets of competencies available to pull from 


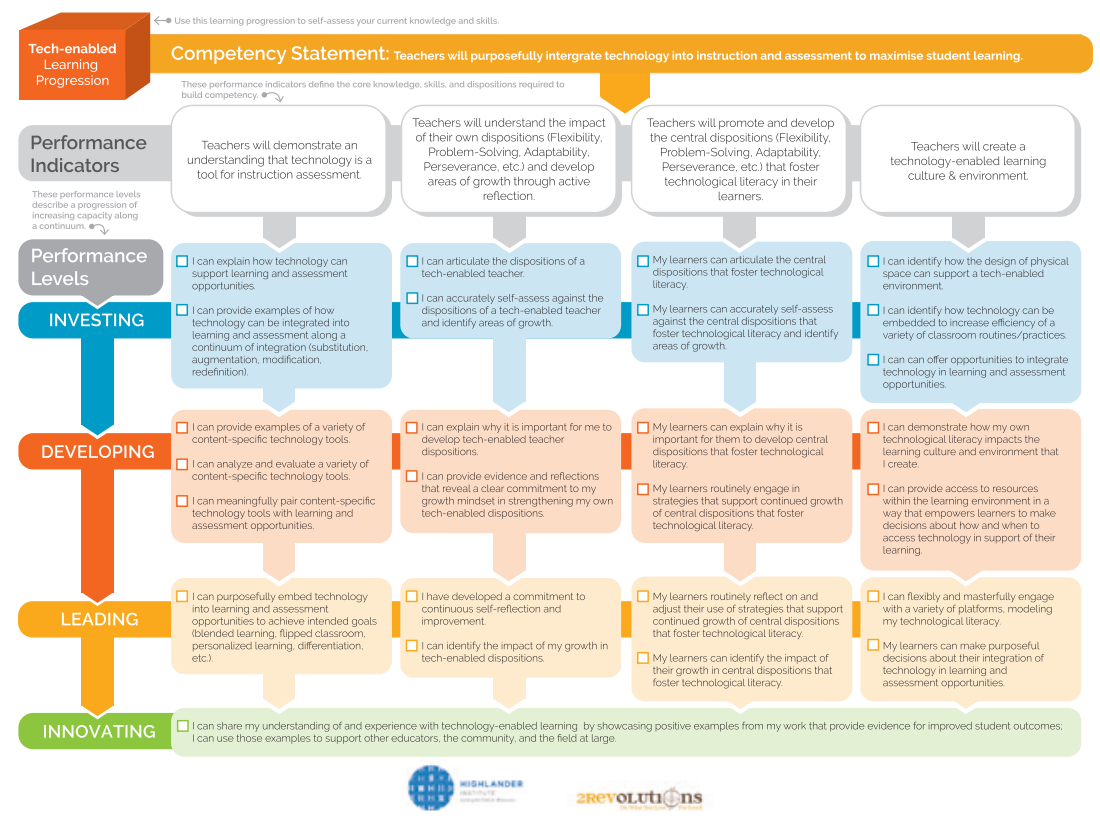

Fig. 7.13 Adult learning progression artifact

(including rich work on more next generation competencies by Jobs for the Future in 2015), this competency development work needs to be anchored to the local context and take into account what the evolving teacher role needs to know and be able to do. In a competency-based context, the output from learning is privileged above actions of learning. Therefore, evidenced-based validations of educator-specific competencies are the aim.

There are a deeper set of more interactive learning opportunities available through topical micro-credentials. These learning experiences provide participants with the chance to demonstrate their knowledge and skill acquisition for credentials, based on the presentation of clear evidences of learning. An educator is able to take a micro-credential learning experience online, which allows them to make variable their pace and place of learning. Participants can take a full micro-credential or just move directly to a formative assessment, which will ask them to present clear evidence of shifted practice within the classroom, through 
relevant artifacts and explanation. This can include student work, video documentation, or some other clear demonstration of learning. As an educator wants to go deeper into a topic, there are "stacks" of multiple micro-credentials, which provide greater depth and allow for demonstrable knowledge and skill development.

Additionally, beyond the demonstrations of learning are opportunities for deeper reflection on practice through an ongoing dialogue with a coach aligned with one's personal learning plan. These plans are living documents with both the educator and the coach going back and forth around knowledge, skills, and disposition development.

The move toward competency-based learning is a significant shift away from measuring time-based learning opportunities, which more often than not had the feel and efficacy of a compliance-based exercise.

\section{ShifTING BeLIefs}

One of the last pieces to fall into place is beliefs. Beliefs are the hardwired cultural elements underpinning one's practice. Training and support, while critical is insufficient until there is ownership over one's learning and evidence of real and lasting student performance shifts. When you run an effective process of adult learning, that embodies the design principles derived in the Next section of this chapter, you are building capacity to shift beliefs.

\section{Promoting Sustainability and Wellbeing}

Rethinking how educators keep growing in their practice through ongoing professional learning represents a significant lever to drive the transformation of systems. This process also offers an opportunity to promote sustainability and wellbeing more broadly for students, educators, and the system itself.

Sustainability represents greater efficiency in the use of resources, which promises doing more with less and extending the impact of efforts. With a more innovative approach to educator training in the Future, there is an opportunity for significant savings in how we spend time within the system and the value of the time we do spend. There are also significant opportunities for economic efficiency in terms 
of the amount of resources spent on professional development and the return on investment of those resources. Beyond the quantitative measurements of time and money, there are both qualitative and quantitative data that we care about deeply such as the ability to attract and retain talent in the sector, thereby promoting greater sustainability for schools and learning models. Each transition of staff has significant economic costs, as well as costs on culture with the loss of institutional memory, cohesiveness of staff, and continuity of relationships between adults and students. There are also opportunities for greater sustainability that can come from reinvesting savings from ineffective and inefficient professional learning experiences to more student-facing expenses.

When we consider how this work contributes to the well being of individuals, there are myriad benefits from rethinking professional learning. For the educators, research provides substantial evidence that happier, more engaged, more respected people have higher rates of job satisfaction across industries (Revesencio 2015). They feel more connected to the work they are doing and will do it better. Retention is higher and opportunities emerge for clearer career pathways to stay meaningfully engaged while afforded the opportunity to play a variety of roles which deepens one's personal investment and maintains interest. The derivative benefits of wellbeing are better professionals who are more motivated to do right by students and more skilled to execute against those desires. Students benefit from this new reality as the recipients of better teaching and learning. As educators have more of the experiences of the learning environments that are better for students-in terms of content, skills, and dispositions-the residual benefits for students will be seen in more dynamic, student-centered learning environments where the focus will shift to a broader definition of student success.

As we see in much of our work, dysfunction trickles down from systems to educators to students. Ultimately, in addition to educators and students, by rethinking professional learning in the ways we have outlined, we have a greater probability of actualizing the kind of transformation we want for student learning. Systems themselves become more sustainable and culturally stronger, healthier places. By anchoring professional learning in respect and professionalism, there is an opportunity to reset the very tenor of how systems work. 


\section{REFERENCES}

Adkins, S. S. (2016). 2015 International Learning Technology Investment Patterns. Monroe, WA: Ambient Insight Research.

American Institutes for Research. (2013). Improving College and Career Readiness by Incorporating Social and Emotional Learning. Washington, DC: American Institutes for Research.

Boston Consulting Group. (2014). Teachers Know Best: Teachers Views on Professional Development. Seattle, WA: Bill \& Melinda Gates Foundation.

Chetty, R., Friedman, J. N., \& Rockoff, J. E. (2011). The Long-Term Impacts of Teachers: Teacher Value-Added and Student Outcomes in Adulthood. Cambridge, MA: National Bureau of Economic Research.

City, E. A., Elmore, R. F., Fiarman, S. E., \& Tetiel, L. (2009). Instructional Rounds in Education: A Network Approach to Improving Teaching and Learning. Cambridge, MA: Harvard Education Press.

Darling-Hammond, L., Wei, R. C., Andree, A., Richardson, N., \& Orphanos, S. (2009). Professional Learning in the Learning Profession: A Status Report on Teacher Development in the United States and Abroad. Stanford, CA: National Staff Development Council \& The School Redesign Network at Stanford University.

Dunne, K. A. (2002). Teachers as Learners: Elements of Effective Professional Development. Stoneham, MA: WestEd.

Dweck, C. S. (2007). Mindset: The New Psychology of Success. New York, NY: Random House.

Dymnicki, A., Sambolt, M., \& Kidron, Y. (2013). Improving College and Career Readiness by Incorporating Social and Emotional Learning. Washington, DC: American Institutes for Research.

Fullan, M., \& Langworthy, M. (2014). A Rich Seam: How New Pedagogies Find Deeper Learning. London: Pearson.

Gulamhussein, A. (2013). Teaching the Teachers: Effective Professional Development in an Era of High Stakes Accountability. Alexandria, VA: Center for Public Education \& National School Boards Association.

Hanushek, E. A. (2011). Valuing Teachers: How Much Is a Good Teacher Worth? Education Next, 11(3), 40-45.

Hattie, J. (2012). Visible Learning for Teachers: Maximizing Impact on Learning. New York: Routledge.

Huang, D., \& Cho, J. (2010). Using Professional Development to Enhance Staff Retention. Afterschool Matters, 12, 9-16.

Jobs for the Future \& the Council of Chief State School Officers. (2015). Educator Competencies for Personalized, Learner-Centered Teaching. Boston, MA: Jobs for the Future.

Joyce, B., \& Showers, B. (2002). Student Achievement Through Staff Development. Alexandria, VA: ASCD. 
Knowles, M. S. (1992). Applying Principles of Adult Learning in Conference Presentations. Adult Learning, 4(1), 12.

Lench, S., Fukuda, E., \& Anderson, R. (2015). Essential Skills and Dispositions: Developmental Frameworks for Collaboration, Creativity, Communication, and Self-Direction. Lexington, KY: Center for Innovation in Education at the University of Kentucky.

Matlach, L., \& Poda, J. (2016). Looking Outside Education: What School Leaders Can Learn About Professional Learning from Other Industries. Washington, DC: Center for Great Teachers and Leaders \& Learning Forward.

McCaffrey, D., Lockwood, J. R., Koretz, D. M., \& Hamilton, L. S. (2003). Evaluating Value-Added Models for Teacher Accountability. Arlington, VA: The RAND Corporation.

National Research Council. (2000). How People Learn: Brain, Mind, Experience, and School (Expanded ed.). Washington, DC: The National Academies Press.

OECD. (2014). Results from TALIS 2013: Country Note, United States of America.

Pane, J. F., Steiner, E. D., Baird, M. D., \& Hamilton, L. S. (2015). Continued Progress: Promising Evidence on Personalized Learning. Santa Monica, CA: The RAND Corporation \& The Bill and Melinda Gates Foundation.

Pink, D. H. (2009). Drive: The Surprising Truth About What Motivates Us. New York, NY: Riverhead Books.

RAND Corporation. (2012). Teachers Matter: Understanding Teachers' Impact on Student Achievement. Santa Monica, CA: The RAND Corporation.

Revesencio, J. (2015). Why Happy Employees Are 12\% More Productive. Fast Company.

Schieb, L. J., \& Karabenick, S. A. (2011). Teacher Motivation and Professional Development: A Guide to Resources. Ann Arbor, MI: Math and Science Partnership-Motivation Assessment Program, University of Michigan.

Sturko, P. A., \& Gregson, J. A. (2009). Learning and Collaboration in Professional Development for Career and Technical Education Teachers: A Qualitative Multi-case Study. Journal of Industrial Teacher Education, 45(34), $34-60$.

TNTP. (2015). The Mirage: Confronting the Hard Truth About Our Quest for Teacher Development. Brooklyn, NY: TNTP.

University of Chicago Consortium on Chicago School Research. (2013). Readiness for College: The Role of Non-cognitive Factors and Context. Voices in Urban Education, 38, 45-52, see as Chicago Research Consortium.

Walberg, H. J., \& Uguroglu, M. (1980). Motivation and Educational Productivity: Theories, Results and Implications. In L. J. Fyans Jr. (Ed.), Achievement Motivation: Recent Trends in Theory and Research (pp. 114-134). New York: Plenum. 
Webb, N. (1997). Research Monograph Number 6: Criteria for Alignment of Expectations and Assessments on Mathematics and Science Education. Washington, DC: CCSSO.

Wiggins, G., \& McTighe, J. (2005). Understanding by Design. Alexandria, VA: ASCD.

Wlodkowski, R. J. (2008). Enhancing Adult Motivation to Learn: A Comprehensive Guide for Teaching All Adults. San Francisco, CA: Wiley.

Open Access This chapter is licensed under the terms of the Creative Commons Attribution 4.0 International License (http://creativecommons.org/licenses/ by $/ 4.0 /$ ), which permits use, sharing, adaptation, distribution and reproduction in any medium or format, as long as you give appropriate credit to the original author(s) and the source, provide a link to the Creative Commons license and indicate if changes were made.

The images or other third party material in this chapter are included in the chapter's Creative Commons license, unless indicated otherwise in a credit line to the material. If material is not included in the chapter's Creative Commons license and your intended use is not permitted by statutory regulation or exceeds the permitted use, you will need to obtain permission directly from the copyright holder.

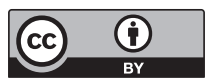

